\title{
CORRECTION
}

\section{Correction: Survival and hospitalization among patients with acute myeloid leukemia treated with azacitidine or decitabine in a large managed care population: a real-world, retrospective, claims-based, comparative analysis}

\author{
B Douglas Smith ${ }^{1 \dagger}$, Charles L Beach ${ }^{2}$, Dalia Mahmoud ${ }^{3 \dagger}$, Laura Weber ${ }^{3}$ and Henry J Henk $k^{4 *+}$
}

After the publication of this work [1], it was brought to our attention that a statement in the article is not consistent with the data. The statement "Prior RBC transfusions were found to significantly increase the time to hospitalization (adjusted HR 1.373, $\mathrm{p}=0.018$ ) while no other covariates examined were found to impact the risk of hospitalization" is not a correct reflection of the results from the data analysis in Table 2 of the article.

The corrected statement is provided here as follows:

"Prior RBC transfusions were found to significantly shorten the time to hospitalization (adjusted HR 1.373, $\mathrm{p}=0.018$ ) while no other covariates examined were found to impact the risk of hospitalization."

\section{Author details}

'Sidney Kimmel Comprehensive Cancer Center at Johns Hopkins, Baltimore, MD, USA. ${ }^{2}$ Hematology/Oncology Clinical Research and Development, Celgene, Summit, NJ, USA. 'Global Pricing and Market Access, Celgene, Summit, NJ, USA. ${ }^{4}$ Health Economic and Outcomes Research, Optum, Eden Prairie, MN, USA.
Published: 16 July 2014

\section{Reference}

1. Smith DB, Beach CL, Mahmoud D, Weber L, Henk HJ: Survival and hospitalization among patients with acute myeloid leukemia treated with azacitidine or decitabine in a large managed care population: a real-world, retrospective, claims-based, comparative analysis. Exp Hematol Oncol 2014, 3:10.

\section{doi:10.1186/2162-3619-3-19}

Cite this article as: Smith et al:: Correction: Survival and hospitalization among patients with acute myeloid leukemia treated with azacitidine or decitabine in a large managed care population: a real-world, retrospective, claims-based, comparative analysis. Experimental Hematology \& Oncology 2014 3:19.

\footnotetext{
* Correspondence: Henry.Henk@optum.com

${ }^{\dagger}$ Equal contributors

${ }^{4}$ Health Economic and Outcomes Research, Optum, Eden Prairie, MN, USA
} 